\title{
Writing the Square: Paul Carter's Nearamnew and the Art of Federation
}

\section{Jennifer Rutherford, Macquarie University}

Ted Hughes tells a story of the Polish poet Milosz lying in a doorway watching the bullets lifting the cobbles out of the street beside him and reflecting: 'that most poetry is not equipped for life in a world where people actually do die. But some is’ (Feldstein 2001, 199). In Milosz's reflection one hears an echo of the question of the ancients, 'How is one to live?' and interior to this question another, 'How is one to write?' Or, 'how is one to write in order to live?' The attempt to answer these questions - to write a poetry for life-is found in many of his poems that return again and again to the question of responsibility to the legacy of the dead, naming them, recording the event of their deaths and the culpability of those who survived in a poetry which is never only that, but which masters an orientation he describes as to 'remain aware of the weight of fact without yielding to the temptation to become only a reporter' (Milosz 2001). In this paper I want to take up this question, posed by Milosz_of a poetry 'equipped for a life in which people actually do die' — to consider what form such a poetry might take in Australia, where whole populations have died, and the culture en masse is intent on keeping the weight of this fact uninscribed.

Robert Manne recalls that in 1968, W.H. Stanner broke a historic silence on the part of the entire Australian social science community in relation to Aboriginal dispossession and its aftermath with a lecture, 'The Great Australian Silence' broadcast on the ABC. That lecture launched a generation of scholars and activists into, as Manne writes, ' a collective work' aimed at shattering the silence (Manne, 2003, 1-2). But while this 
collective work continues, the public openness to this epoch of 'truth-telling' appears to have closed. The election of the Howard government for an historic fourth term underlines a collective tolerance for his concerted campaign to restore the myths of Australian history. His refusal to apologise to the victims of the stolen generation, the labelling of the testaments of Aboriginal experience as 'black-armband history' and his expressed determination to take 'identity' off the national agenda in order to make Australians 'comfortable' has undoubtedly found an audience with those many Australians who wish for simple stories and residence in an heroic past. For them, better Howard's battlers and pioneers than uncomfortable truth telling about stolen children and entrenched and institutionalised racism. And what chance the truths of the past when the lies of the present - the children overboard affair, the myth of weapons of mass destruction—-make no dint in Howard’s popular appeal?

This deep inhospitality in contemporary Australia to acts of parrhesia — of truth sayingchallenges the creative imagination to generate new forms of speech, writing and formgiving that speak to the cocked ear of the future. But what forms of speech might be generated that can navigate a path through the compressed spaces of the present? And how can speech itself create concrete effects at a time when acts of testimony, story telling and critical argument appear to leave no trace? If Australia is, as Peter Read reminds us, 'a storied country' (2003) how can spaces be created for these stories to be told - and heard? One answer to these questions - and they are questions that need many answers - is given in the form of nine concrete poems that mark time in Melbourne's Federation Square. 


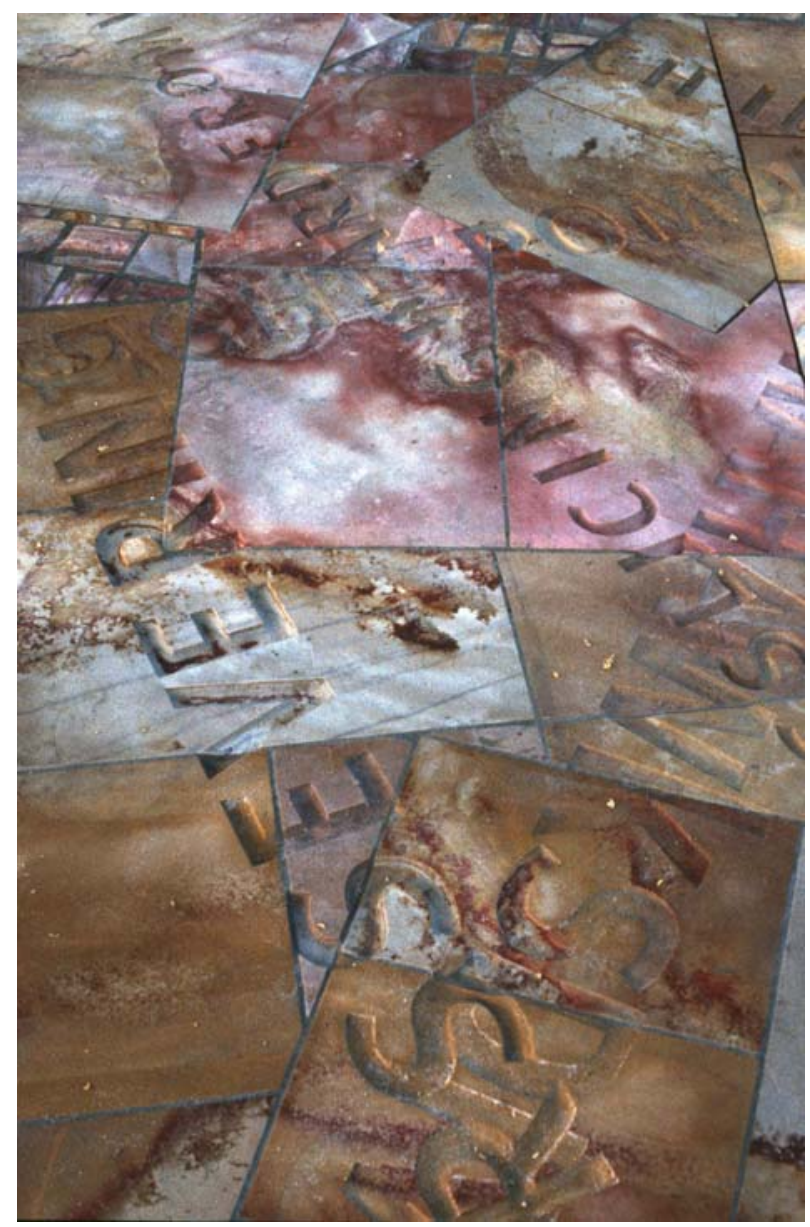

Paul Carter in collaboration with Lab architecture studio, Nearamnew, Federation Square, Melbourne (2003), detail. Photo: Paul Carter. Reproduced with permission

Australia approached the centenary of Federation in 2001 in those dark years of the late nineties. Years that evinced de Certeau's words: 'the past it rebites' (2001, 3-4). One hundred years after Federation the demands that had led to the infamous white Australia Policy resurfaced in Pauline Hanson's maiden speech in Federal parliament in 1997—the speech that inaugurated a far-right popular mass movement-Hanson declared: 'If I can invite who I want into my home then I should have a say in who comes into my country'(Hansard 10 September 1996). In the federal election of 2001, the Howard Government, riding the billy-cart of Hansonism, seized an election victory with full-page advertisements that read, 'We will decide who comes to this country and the circumstance in which they come ' (Liberal Party, 2001). These were the demands (to 
control the influx of 'aliens') that had been the rallying cry for the newly imagined nation inaugurated in Australia's Federation in 1901.

When the conservative Kennet government of Victoria commissioned Lab, a London based architecture firm to design a public place in the heart of Melbourne to commemorate Federation, one might have anticipated the mythmakers to seize the moment to concretise a heroic and linear vision of Australia's past. Instead a complex structure of radical conception was designed for the site and postcolonial theorist and public artist Paul Carter commissioned to create an artwork to mark the site 'as a focus of historical, social and political negotiation' (Carter 2002, 404). While social and political controversy waged over the external and visible structure of Federation Square, Nearamnew slipped almost unnoticed into residency. Nearamnew is a quiet work cut into the sandstone cobbles that line Federation Square. Walking quickly over the hill and dale surface of the square you could walk right over Nearamnew and not notice what was below your feet. Perhaps it is this quietness that has allowed the work to come into being or is it that like Poe's purloined letter, Nearamnew hides by being present to view? Certainly the quietness of the work—a speaking underfoot—figures the history of the stories the work gives voice to. Perhaps those who might have protested at the stories the work tells, walked too quickly or didn’t pause between strides to hear the ground speak. 


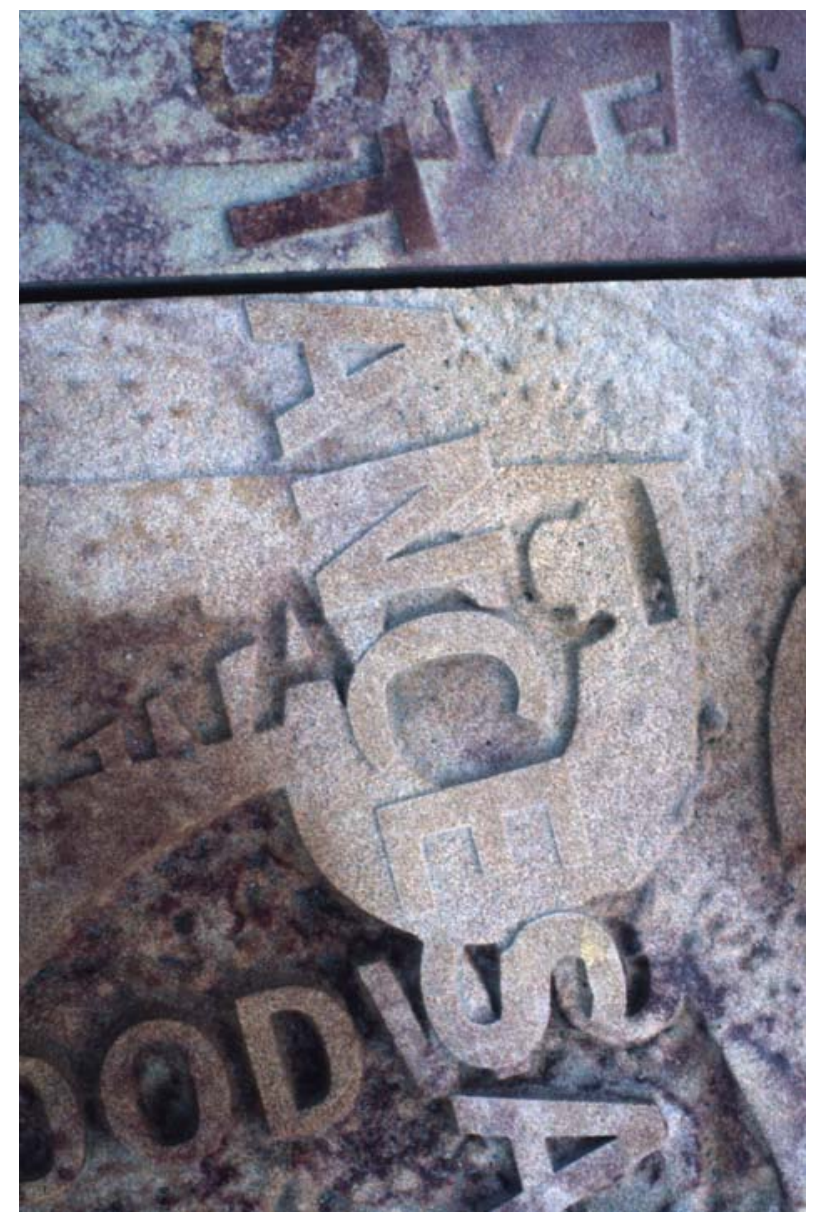

Paul Carter in collaboration with Lab architecture studio, Nearamnew,

Federation Square, Melbourne (2003), detail. Photo: Paul Carter. Reproduced with permission

Carter's concern has long been the ground, or in his words the lie of the land; the echoes and murmurings of a ground that continues to speak despite the 'haussmanisation' of colonial practice. In diverse creative acts ranging from public art works, sound installations, and performance pieces to the spatial histories of The Road to Botany Bay, and The Lie of the Land, Carter has attempted to speak a dwelling space into existence where imperial history and its clearings have deprived us of a house of being. We could characterize his work as an attempt to make its auditors hear differently, to hear the already said, the lost speech that colonial practice silences. Carter calls this practicing an art of the gap, which he understands as the structural counterface of colonial discourse. His art of the gap is an art for the post-colonial subject dislocated, homeless and resident in the symbolic and imaginary confinement of 'abysmal discourse'; the discourse a culture such as white Australia generates to occlude its own history of colonisation, 
systematic genocide and silencing. This includes the discourse that cuts a path in the land itself clearing and erasing every physical trace of Aboriginal inscription. '.. As the colonist advances in this way', Carter writes, 'he wipes out every sign of difference, covering up the swerve of historical experience, reducing the land to a blankness. His corrupted travel clears the way for representing the world in a table.' For Carter to be 'in the gap' is to refuse residence in this abysmal discourse and hence to be in the truth of white-Australian culture 'laid bare’ (Carter n.d., 'Beyond').

This opposition between abysmal discourse and an art of the gap structures Carter's poetics; a poetics he clarifies as an art of speech rather than of writing, or of speech-filled writing. His argument is that in the same way colonisation clears the land in order to write its own monologic text as if on a tabula rasa, writing takes out the noise of speech. In Australia the first acts of writing involved suppressing the untranslatable, irreducible elements of cultural difference. Land was cleared, the country silenced, speech reduced to monologue. In writing, unlike in dialogue, no other answers back, no other refuses the story being told of the world. For Carter, writing homogenises and decontextualises language from the social and visceral flux of living bodies. It stabilises linguistic form and in doing so it concretises and fixes meanings and social relations. Carter concurs with Lacan that it is through language that the other is reduced to an image of homogeneity. But while Lacan puts the emphasis on language itself and the mirroring potentiality of speech, Carter argues that the dialogic nature of speech—in contrast to writing — has the potentiality to recall the other side of language. This to and fro of dialogue has an irreducibly visceral component. In speaking one encounters the other in their corporeality—bodies speak to bodies—and language overflows the passage of words. Because of this unruliness speech has the potential to betray the speaker, to speak beyond rational intention and in speaking face á face with an 'Other' to bring the social nature of speech into view.

In this interface of speech and writing Carter situates an imagined encounter. For Carter there is a madness afoot in the colonial situation itself, which dislodges language and allows speech momentarily to sound. In the colonial context, European culture loses its 
frame; meaning loses its reference, its familiar rhetorical systems and its linear surety. It crosses a line. He writes: 'Kant notices that it is commonly said of someone whose mind has stepped over the border: "he has crossed the line" just as if a man who crossed the equator for the first time were in danger of losing his understanding'(Carter, n.d., 'Beyond'; Kant, 1974). This spatial dislocation of colonisation engenders a bouleversement of reason and its limit, but madness is on the side of Kantian reason, and to cross its limit is to open a dialogue, a potentiality. Carter imagines an encounter in this moment when two cultures that don't share a language have to communicate. He is interested in communication that can’t proceed in a normative environment and in the way communication straining in the absence of a shared language reveals aspects of normal communication lost to our perception. When two cultural groups meet, sympathetic identification enables them to take advantage of mere coincidences and grammatical similarities in order to improvise a discourse. New forms are created out of the phonic convergence of the two languages. Carter's stress is on the performative nature of speech at the moment of this encounter when mimetic gesture, intonation, repetition and identification become the visible foundation of communication. He is not suggesting that this is the form of the colonial encounter, but its potentiality-a potentiality lost through the monologic drive of white culture to write out the speech of the other. The task that he sets himself is to recall this speech in writing; a speech-filled writing that in its gaps will forge an encounter between the reader and the unheard speech of both self and other.

To practice an art of the gap then, is to be recalled to these lost moments of dialogue written over by white Australian culture, and in recognising the self in them, to begin to devise a speaking position as a new place of residence. What Carter is attempting in this formulation of an ethics and a writing of the gap is a new theoretical articulation of the art of becoming oneself. To practice an art of the gap is to find voices in the past that answer to one's condition and in being witness to these voices to begin to become oneself. 


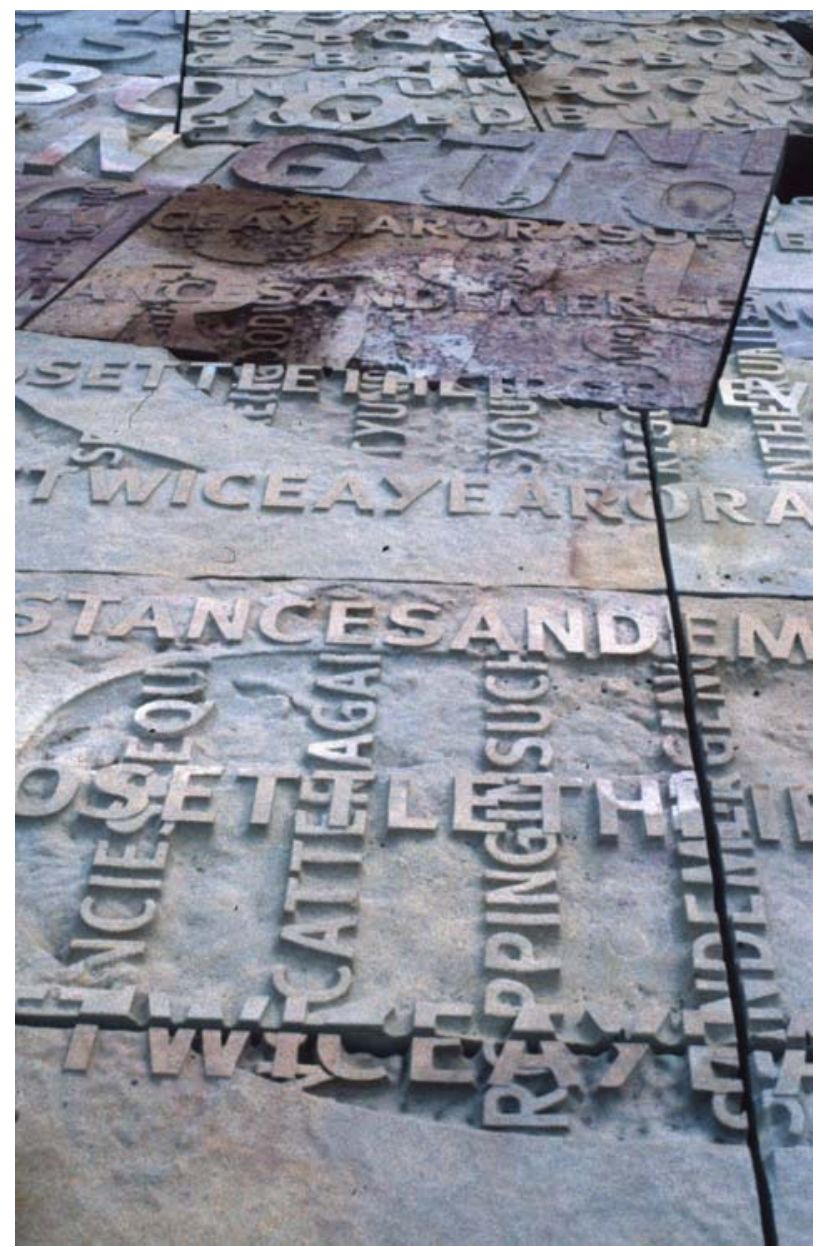

Paul Carter in collaboration with Lab architecture studio, Nearamnew,

Federation Square, Melbourne (2003), detail. Photo: Paul Carter. Reproduced with permission

If bullets can lift cobbles out of streets and lives out of bodies what of a work of poetry that lays down cobbles and revoices a square with lost lives? Nearamnew is a work inscribed in the cobblestones of Federation Square consisting of nine regional forms constructed out of the letters that name the site — each containing a local vision of Federation. These regional forms and their embedded concrete poems are three dimensional. Cut into three depths of the surface of stone each layer of text interconnects diagonally and vertically. The letters run into each other and the words themselves breakup and entangle into different patterns as they repeat and intermix in the rock-face. Read linearly, they are anacoluthon, scrimped and yet eerily beautiful; but because of their form, the interconnections and fragmentations of the poems, they are 'word shards' resisting any linear or incorporative approach to their meaning. One can't 'eat these words'. They can only be introjected, approached relationally, and partially, as one makes 
out patterns of meaning within the fractal patterns of the work. Uncannily, they are etched in the calligraphy of the gravestone so that one is viscerally and visually in the field of death, but the rock-face is alive with voices - many voices singing in the rock.

This structural form calls forth a type of reading that Carter calls treading; the reader performs the work through the act of treading its surface. To tread Nearamnew one has to get down on one's hands and knees and clamber over the surface of the ground deciphering the songs that sound in the rock by tracing out their letters in a braille that hovers between a language one knows and a linguistic form one cannot identify.

Knowing and unknowing, the reading is slow, the memories it conjures partial and the grasp of the text always there at the edge of one's reach. Elsewhere, Carter has written that we need to slow the pace to hear what is between two strides. He recalls the peculiar stride of Beckett's character, Watt:

Watt's way of advancing due east, for example, was to turn his bust as far as possible towards the north and at the same time to fling out his right leg as far as possible towards the south, and then to turn his bust as far as possible towards the south and at the same time to fling out his left leg as far as possible towards the north, and then again to turn his bust as far as possible towards the north and to fling his right leg as far as possible towards the south . . . and so on, over and over again, many many times, until he reached his destination, and could sit down (Beckett 1953, 30).

Watt's stride, curious, ungainly and awkward, seems destined not to arrive. It twists the body on its own axis slowing locomotion to a parody of human movement-two legs moving widdershins to will. There is something of this arrested stride in all of Carter's writing where he delays the reader intent on action and on a narrative that reaches its end. Carter wants to stall his reader's intention in the form of the saying, to slow the reader down in their anticipation of the writer's linear intention. His style intends if not to paralyse, then at least to arrest the reader in the space between two steps; and in this pause where meaning falters to forge an encounter between the reader and something new. In Nearamnew this space between two strides is rendered literal; one cannot read the text if one keeps walking. 


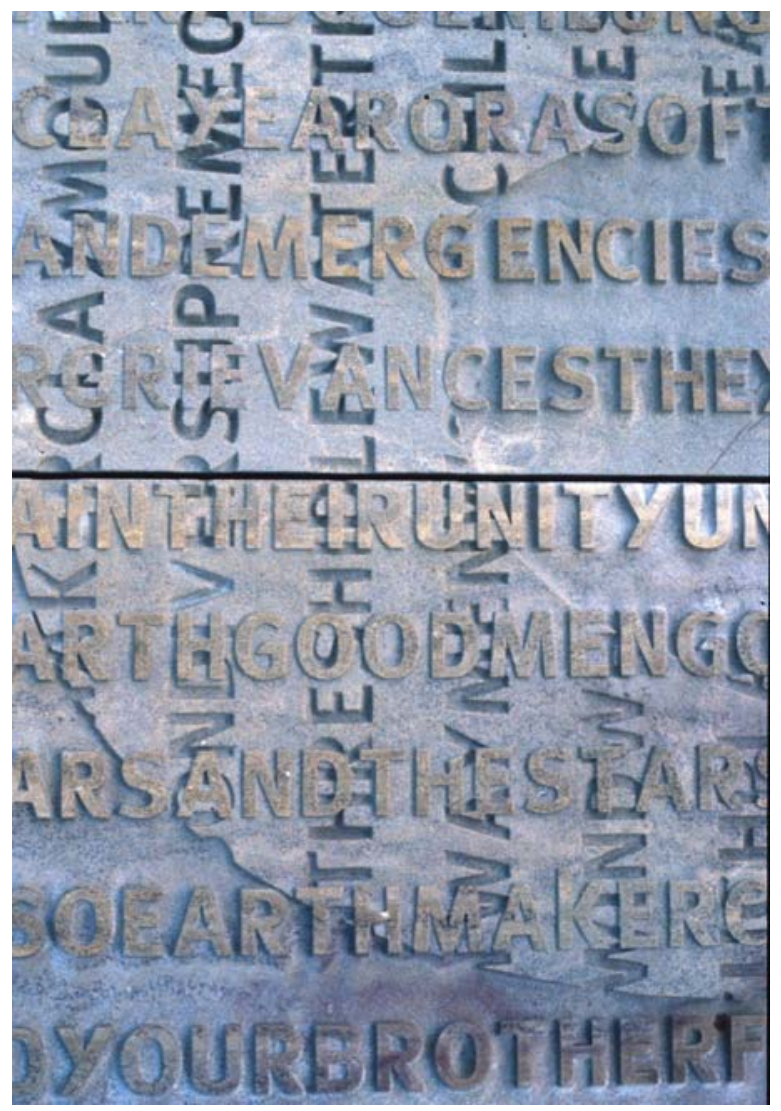

Paul Carter in collaboration with Lab architecture studio, Nearamnew,

Federation Square, Melbourne (2003), detail. Photo: Paul Carter. Reproduced with permission

The form of Nearamnew is a global whorl pattern taken from an etching composed of braided lines folding over themselves representing water flowing between Tyrell Creek and Tyrell Lake. These lines of turbulence were created by a Boorong artist as a bark etching made near Lake Tyrell around 1860. What justifies incorporating the artist's design into Nearamnew - making it in fact the form of the work-is not the formal and aesthetic convergences between the pattern and a federal system but rather, Carter argues, that the etching was made in a time of crisis and was a sophisticated attempt to create a mytho-poetic form in postcolonial circumstances. Carter understands mytho-poetic work as occurring at a time of crisis when myth has been forgotten or no longer works and in this sense Nearamnew attempts to create a new myth-form for a Federated society, when the old myth of Federation no longer holds. In this he draws on the earlier work as an attempt by an artist to generate a culturally and environmentally sustainable myth form. The original etching integrated elements of white settler culture, technology and scenes of 
indigenous social and ceremonial life and as such, attempted to create a place of collective renewal. Like Nearamnew it tried to create 'places made after story'.

'Creating place made after story' is one answer to the question I posed at the beginning of this article: How is one to write in order to live? Nearamnew is a poetic act that creates the place of Federation after story; it remains true to the weight of the past but is never merely reportage. As Carter writes: 'There is no writer apart from the matrix of language: and the writer merely recognises the pattern inherent (unopened) in what lies around, and slashing this way and that way with his knife, and sewing and sewing, identifies a possible plot or ground' (Carter, n.d., 'Nearamnew'). Nearamnew's poems are created from fragments of forgotten language, Carter's own voice as writer submerged by these other voices that he brings into poetic dialogue. Central to this reconstitution of already given stories is the refiguration of the story of the nation's federation within an already storied place. Instead of commemorating the moment in colonial history when the nation is inaugurated, this moment fits back into a richly historied past in which Aboriginal federal systems embodying a federal vision of social organization provide the form of the work and its many voices. Commemorating Federation creates a testimony to the idea of federation as it structured Aboriginal society and engenders a forward thinking imaginary of what a properly federated future might be; a system of interconnectedness with the global, regional and local balanced, in dialogue, intermixing and mutually respectful. Carter writes: 'Lines of communication and exchange within a Federal system are often likened to the turbulence patterns in clouds and water, decisions form at the heart of whirlpools, groupings of people produce what are called dissipative structures, leading to the emergence of new places of civility, sociality, and empowerment' (Carter, n.d., 'Nearamnew').

This act of remembering Aboriginal federated systems of social organization involves what Carter calls 'remembering forward', or remembering the past in order to imagine the future differently. Just as the migrant must carry their past with them and live between the two worlds of past and future Carter remembers forward retrieving fragments from the past that allow us to live in the movement towards a different future. 
The melancholic act of remembering Federation and its stain of racism and disposession transforms into an act of mourning. The past and its brutalities are not elided (they are there inscibed in the rock) but nor are we locked into an untraversable and hence encrypted memory of Federation and its acts of white nation formation. The act of Federation looses its monumental status. Alfred Deakin's place of Federation becomes only one moment in a long history in which the site of Federation Square has long been a meeting ground for a federated society. Place becomes differently told. Each word shard in each concrete poem sounding a story fragment that recalls or echoes different pasts.

In the first words of 'The Maker's Vision' for example, 'o earth maker clay mould of man' the story of Bunjil sounds, who the Aborigines of the Yarra, say, made the earth. 'He went all over it with (with his knife or sword, cutting it in many places and thereby formed creeks and rivers and valleys.' Or in another form of the story-'Pundjel made of clay two males’ (Carter 2002, 1 [fn 1]; reference to Brough Smyth, 1972, 423). A recorded scrap of dialogue tells a different story of beginning - 'In time men and women became very numerous and they were wicked Pundjel punished their wickedness, entering their escarpments and cutting men and women into small pieces however the pieces did not die but moved as the worm moves and great whirliwinds came changing them into flakes of snow which were carried over the earth.' 'The surface figure into which this text is inscribed' Carter writes, 'imitates this process of multiplication through self-division. At the beginning the text repeats itself, it produces more words which in turn scatter into more. But as the words are flung out from their source, they diminish in size settling into the warp and weft of a moiety woven society.' (Carter, n.d., 'Nearamnew', 25).

In another poem, 'The Child's Vision', hopscotch symbolises the lines that arbitrarily mapped the country, lines the child leaps over in a game of hopscotch. This act of hopscoth perhaps best characterises the game at the heart of Nearamnew. It is a work that thinks anew; hopping over the story lines of white history, jubilantly making up a new game of story. It makes stories for the future without forgetting the past. In 'The Colonist's Vision' the rock speaks the unbearable destruction colonisation has caused: ‘ 
thirty tomahawk's dividing limb from limb/ knives slicing ward from ward /man from child/ scissors severing night from day/stars tear out their hair/yarra branches bleed/ tight lipped rock splits and roars/20 pairs of blankets cannot bandage up the ground/ 200 handkerchiefs cannot stay quell tamp or dam this spirit cleaving flood.'

One can crawl over the text and reconstitute its stories although any act of treading will give only a partial reading. One enters a text that like language, memory and history is greater than the stories anyone of us can know or remember. The monumental, linear and singular vision of history collapses into multiples. And it is this very idea, of more than one that has rocked contemporary Australian society with its reseizure of the idea of 'One Nation, One People, One Language', and one memory path... Against this vision of One are metaphors running through the square like the idea of the square mirroring the night sky, its whorl pattern of words, a constellation embedded in the universe of rock, or another of a word trail spilling down the Yarra and sedimenting in the plain of the square. There are love trails too scattered throughout the text promising a way forward out of a history of cutting and clearing: ' take my hand/ my word/I want your company/then treat me tenderly/the track is life/near, there and far spreading...'

Remembering forward Nearamnew imagines a time when all these stories will come to light, when children will play its game, deciphering its many puzzles, when migrants, visitors, artists, makers and even colonists will come to a new understanding of place through treading the stories of the Square. Its hundreds of word shards testify to the weight of fact, and recall and recast that fact in a poetic form that writes itself viscerally, erotically, joyously and mournfully on those who tread its paths. And for those who walk too quickly, it remains, silently insistently there cut into the rock waiting for a pause when the nation might once again hear in the space between two strides. Speaking and respeaking a new a homeland into being Carter has created a work in which words mark home or, as Milosz writes, in which—'to find my home in a sentence, concise, as if hammered in metal' $(2001,452)$. In the word shards of Nearamnew there are many homes and all of them cut into rock. 


\section{Reference List}

Australia, Parliament, House of Representatives, Official Hansard 10 September 1996. Beckett, S. 1953, Watt, Grove Press, New York.

Brough Smyth, R. 1972 (1878), The Aborigines of Victoria: with notes relating to the habits of the natives of other parts of Australia and Tasmania compiled from various sources for the Government of Victoria, John Curry, O’Neill, Melbourne.

Carter, P n.d., 'Beyond Nostalgia'(unpublished material that informed the draft of Material Thinking).

- n.d., unpublished notes to 'Nearamnew'. 2002, 'Inscriptions as Initial Conditions; Federation Square (Melbourne Australia) and the silencing of the mark' in Inscribed Landscapes, eds B. David \& M. Wilson, University of Hawaii, Hawaii. 2004, Material Thinking: the Theory and Practice of Creative Research, Melbourne University Press, Melbourne.

Certeau, M. 'Psychoanalysis and its History' in Heterologies: Discourse on the Other, trans. B. Massumi, Theory and History of Literature, vol. 17, University of Minnesota Press, Minneapolis.

Feldstein, E. 2001, Ted Hughes: The Life of a Poet, Weidenfeld \& Nicholson, London. Kant, I. 1974 (1798), Anthropology from a Pragmatic Point of View, trans. M.J. Gregor, Martinuis Nijhoff, The Hague.

Liberal Party 2001, media campaign advertisements that appeared in Sydney Morning Herald prior to the 2001 Australian commonwealth election.

Manne, R. 2003, 'Introduction', in WhiteWash: on Keith Windschuttle's Fabrication of Australian History, ed. R. Manne, Black inc. Agenda, Melbourne.

Milosz, C. 2001, New and collected Poems 1931-2001, Allen Lane, the Penguin Press, London.

Read, P. 2003, Haunted Earth, UNSW Press, Sydney. 